\title{
The PRISM Model/Data Cooperative: Mid-Pliocene data-model comparisons
}

Mark Chandler ${ }^{1}$, H. Dowsett ${ }^{2}$ and A. Haywood ${ }^{3}$

${ }^{1}$ Columbia University, NASA/GISS, New York, USA

United States Geological Survey, Reston, Virginia, USA; hdowsett@usgs.gov

${ }^{3}$ School of Earth and Environment, University of Leeds, UK

The mid-Pliocene ( 3.3 to $3.0 \mathrm{Myr}$ ) has become an attractive target for climate modeling studies, as the dynamics of past warm climates provide a potential guide to understanding future climate change. This interval was selected for detailed study because it spans the transition from relatively warm global climates of the Early Pliocene, when glaciers were greatly reduced in the northern hemisphere, to the generally cooler climates of the Pleistocene, with expanded northern hemisphere ice sheets and prominent glacial-interglacial cycles. The US Geological Survey (USGS) Pliocene Research, Interpretation and Synoptic Mapping (PRISM) Project has documented the characteristics of mid-Pliocene climate on a global scale, and several model-data studies based on PRISM data have been funded by the National Science Foundation (NSF), the National Environmental Research Council (NERC), and NASA.

\section{Initial paleoenvironmental reconstruction}

Four generations of PRISM paleoclimate reconstructions (PRISM0-PRISM3) have evolved from studies summarizing conditions at a large number of marine and terrestrial sites (e.g., Cronin and Dowsett, 1991; Poore and Sloan, 1996). Prior to PRISM0, Dowsett and Poore (1991) analyzed microfossil data from a series of North Atlantic cores and concluded that although the modern North Atlantic differs little from the Last Interglacial, it is cooler than the mid-Pliocene. Middle and high latitudes were warmer during the mid-Pliocene than either the Last Interglacial or the present day (Dowsett et al., 1992). However, low latitudes showed no change during climate extremes (Last Glacial Maximum, Last Interglacial and mid-Pliocene), favoring increased meridional ocean heat transport over increased $\mathrm{CO}_{2}$ as the primary forcing behind midPliocene warming.

\section{Iterative data-model approach}

As the USGS expanded its data sets beyond the North Atlantic and beyond the marine realm, mid-Pliocene northern hemisphere boundary conditions began to take shape. It was a significant, multiyear effort to bring together formerly disparate research projects and construct full global data sets, so the first mid-Pliocene climate simulations were run (with the NASA/GISS atmospheric GCM) using only the completed northern hemisphere data (Chandler et al., 1994). Data from the Pacific and circum-Arctic regions (Barron, 1992a, b; Ikeya and Cronin, 1993; Cronin et al., 1993) were used to produce the first northern hemisphere SST analysis for the mid-Pliocene (Dowsett et al., 1994). Much of the design and production techniques for these digital data sets were developed at this time, leading to the framework for our long-term, iterative, data/modeling approach.

These early simulations were justified on the basis that: 1) they employed only specified surface conditions, 2) the available mid-Pliocene tropical data showed little change from modern, and 3) our focus was on northern hemisphere highlatitude effects. The simulations showed global mid-Pliocene warmth, similar to temperatures forecast for the $\mathrm{mid}-21^{\text {st }}$ century.

The first global reconstruction, PRISM1, was based on 64 marine and 74 terrestrial sites; it included annual vegetation, land-ice, monthly SSTs and sea-ice, sea level, and topography (Dowsett et al., 1996; Thompson and Fleming, 1996). Warming was greatest at high latitudes and during winter, with meridional temperature gradients decreased by $10^{\circ} \mathrm{C}$ and driven largely by decreased ice and snow cover (Sloan et al., 1996). Low latitudes were largely unchanged, though significant cool and wet anomalies over Africa made it clear that details of regional climate were significant for comparisons to both local proxy studies and to future climate change. The hydrological cycle intensified over the continents but actually weakened, on average, over the oceans. This feature distinguished the mid-Pliocene from future global warming simulations, and emphasized the importance of proxy temperature data (e.g., Wara et al., 2005) that suggest warmer eastern equatorial Pacific temperatures. However, PRISM1 data-modeling comparisons have supported independent proxy data that show increased mid-Pliocene meridional ocean circulation (MOC) and associated heat fluxes.

PRISM2 (Fig. 1) incorporated additional marine sites, re-calibration to a common modern SST climatology, new sea level estimates, and a new land-ice configuration (Dowsett et al., 1999; Dowsett, 2007). Model simulations using specified surface conditions from PRISM2 data have largely confirmed results from studies using PRISM1. However, more significantly, the PRISM2 data set provides initial conditions for a series of fully coupled oceanatmosphere model (OAGCM) simulations. The use of coupled OAGCMs is essential to the exploration of mechanisms for midPliocene warmth, such as the possible role

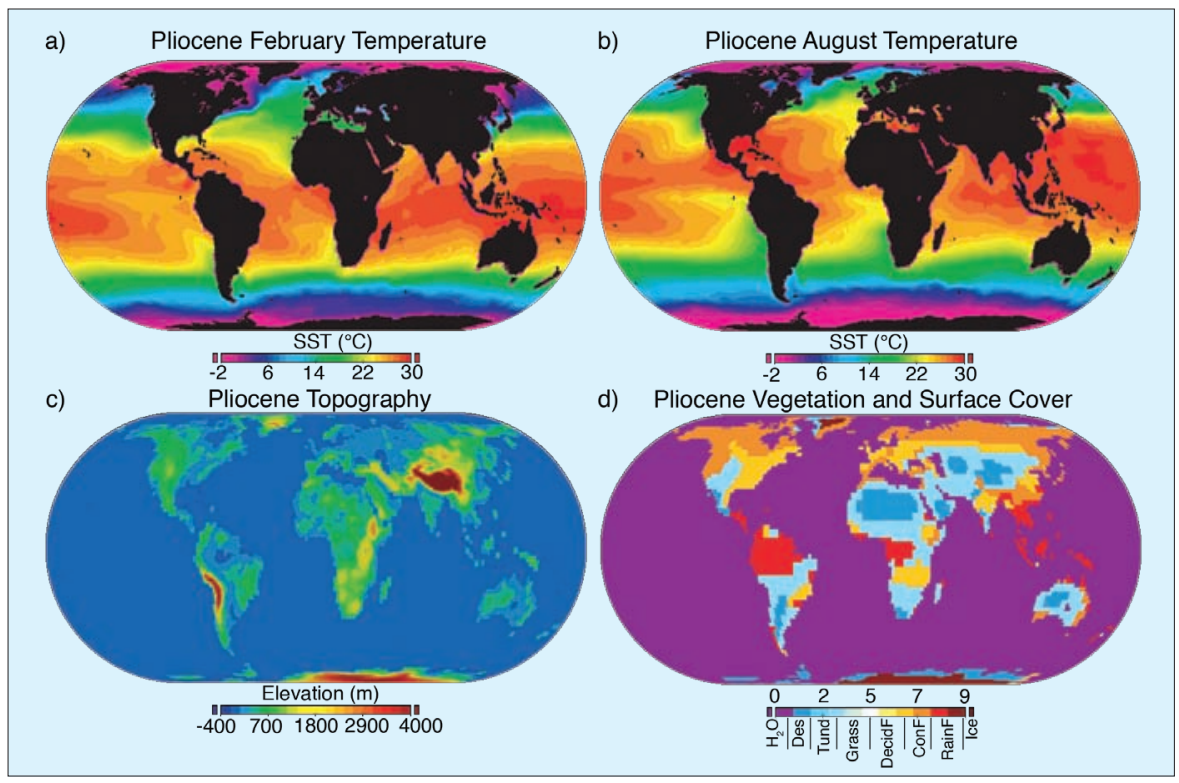

Figure 1: Summary of the PRISM2 paleoenvironmental reconstruction (modified from Dowsett, 2007); a) Pliocene February SST; b) Pliocene August SST; c) Pliocene topography; d) Pliocene vegetation/land cover. 
of enhanced thermohaline circulation (THC), and to model evaluation. Haywood and Valdes (2004) presented the first fully coupled ocean-atmosphere mid-Pliocene simulation, which showed global surface temperature warming of $3^{\circ} \mathrm{C}$ over preindustrial values. In contrast to previous modeling experiments, surface temperatures warmed in most areas, including the tropics $\left(1-5^{\circ} \mathrm{C}\right)$. The model predicted a general pattern of ocean warming $\left(1-5^{\circ} \mathrm{C}\right)$ in both hemispheres to a depth of 2000 $\mathrm{m}$, below which no significant differences were noted. Analysis of the model-predicted MOC indicated a weaker THC. Diagnostics for heat transport indicated that neither the oceans nor the atmosphere transported significantly more heat in the mid-Pliocene. Rather, the major contributing mechanism to mid-Pliocene warmth was the reduced extent of high-latitude terrestrial ice sheets (50\% reduction on Greenland, 33\% reduction on Antarctica) and sea-ice cover, specified by the PRISM2 data set, resulting in a strong ice-albedo feedback (Haywood and Valdes, 2004). The model-predicted response of the THC is opposite to that interpreted from the mid-Pliocene SST reconstruction (e.g., Dowsett et al., 1992; Dowsett et al., 1996). While simulating increased SSTs in many regions, the model appears to underestimate the change at mid-latitudes (Fig 2a). This apparent data-model mismatch is an important issue to examine in terms of model dependency, model initialization, length of model run, uncertainty in paleoceanographic reconstruction, and the internal consistency of the PRISM data set as a whole.

\section{Future of the PRISM Model/Data Cooperative}

PRISM3, still in development, incorporates multiproxy re-examinations of SST (with maximum and minimum peak SSTs providing a climatological error bar), revised land-ice and vegetation schemes based on independent vegetation and ice models, and deep-ocean temperature (DOT) reconstructions based on $\mathrm{Mg} / \mathrm{Ca}$ paleothermometry (Cronin et al., 2005; Dowsett et al., 2005, 2006; Hill et al., 2007; Salzmann et al., 2008). Nearly all of the coupled GCMs used in the IPCC multi-model ensembles for future climate change show a temperature rise in the North Atlantic lagging other high- and mid-latitude regions. These results do not rule out an eventual equilibrium state similar to the warm North Atlantic of the Pliocene but some of the same coupled-GCMs find a similar cool anomaly in mid-Pliocene simulations, at odds with proxy data. Initial experiments using beta

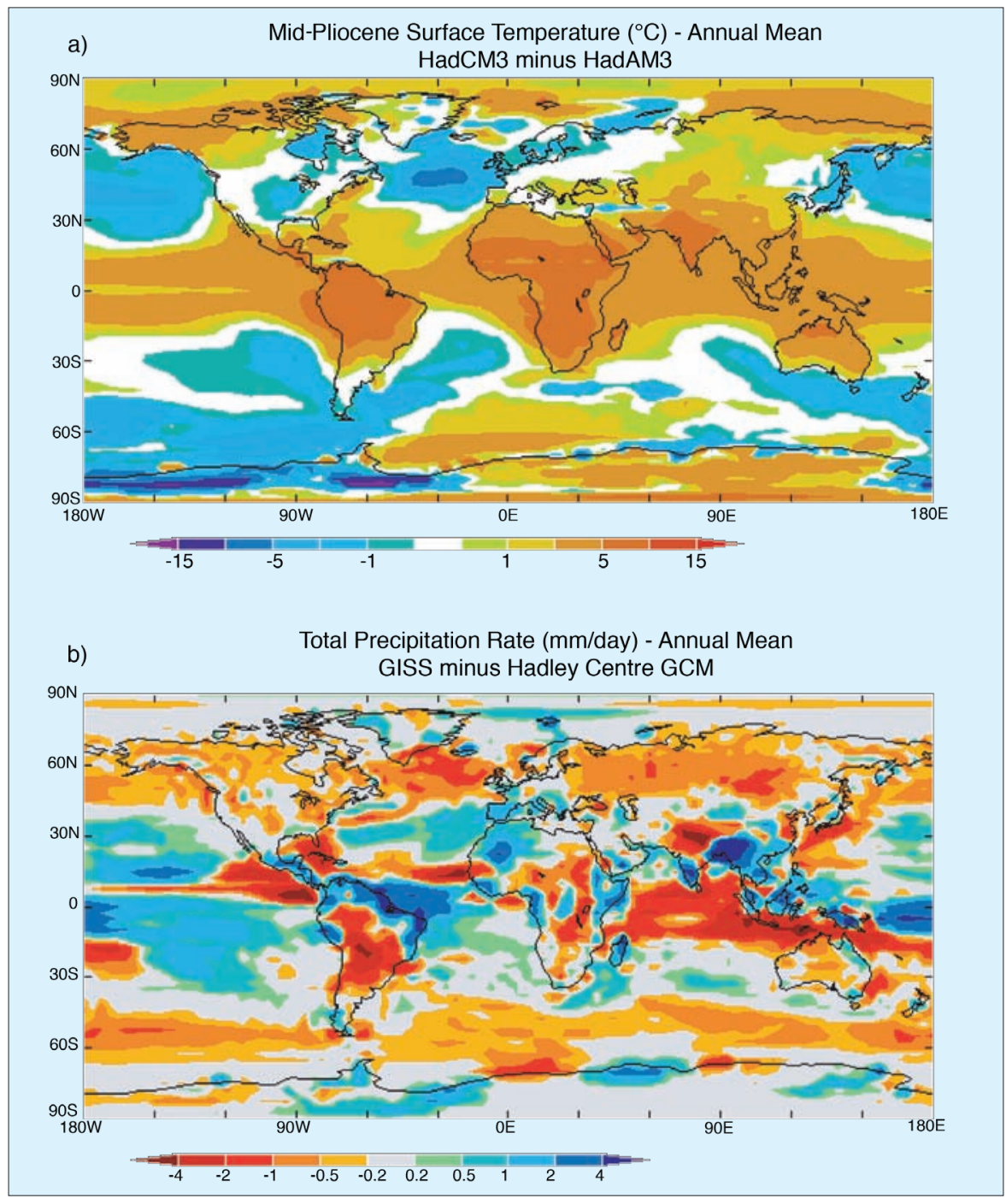

Figure 2: a) Difference in mid-Pliocene annual mean surface temperature $\left({ }^{\circ} \mathrm{C}\right)$ between a fully coupled ocean atmosphere GCM simulation using HadCM3 and an atmospheric general circulation model simulation using fixed PRISM2 SSTS and the HadAM3 GCM. Note the coupled ocean atmosphere model HadCM3 predicts higher surface temperature in the tropics and relatively cool conditions in parts of the mid-latitudes, particularly over the North Atlantic and Pacific Oceans (modified from Haywood and Valdes, 2004); b) Difference in annual mean total precipitation rate ( $\mathrm{mm} /$ day) between the GISS and the Hadley Centre GCMs for the mid-Pliocene. Note the reduction is precipitation in storm track regions in the GISS GCM and the shift in location of the Indian Monsoon.

versions of the PRISM3 DOT data to initiate simulations show an increase in MOC compared to simulations that are initiated with PRISM2 SSTs and modern deep ocean temperatures.

A pilot intercomparison is already underway between the GISS and Hadley Centre GCMs using prescribed boundary conditions from the PRISM2 data set, with a simulation using the CCSM to follow shortly (Fig. 2b). The first planning meeting for a mid-Pliocene model intercomparison project, part of PMIP, has been arranged for early June 2008 at the NASA Goddard Institute for Space Studies in New York. Further announcements will be made through PMIP and PAGES. More information on the PRISM reconstruction can be found at http://geology.er.usgs. gov/eespteam/prism/prism3main.html

\section{Acknowledgements}

The PRISM Model/Data Cooperative is made possible due to continued support from the
U.S. NSF, Paleoclimate Program Grant No. ATM0323516, USGS Earth Surface Dynamics Program, NASA Climate Modeling Program, and NERC.

\section{References}

Chandler, M., Rind, D. and Thompson, R., 1994: Joint investigations of the middle Pliocene climate II: GISS GCM Northern Hemisphere results, Global and Planetary Change, 9: 197-219.

Dowsett, H.J., 2007: The PRISM Palaeoclimate Reconstruction and Pliocene Sea-Surface Temperature. In: Williams, M., et al., (Eds.), Deep-time perspectives on climate change: marrying the signal from computer models and biological proxies, The Micropalaeontological Society, Special Publication, The Geological Society, London, 459-480.

Dowsett, H.J., Thompson, R.S., Barron, J.A., Cronin, T.M., Fleming, R.F., Ishman, S.E., Poore, R.Z., Willard, D.A. and Holtz, T.R., 1994: Joint investigations of the middle Pliocene climate l: PRISM paleoenvironmental reconstructions, Global and Planetary Change, $\mathbf{9}$ : 169-195.

Haywood, A.M. and Valdes P.J., 2004: Modelling Pliocene warmth: contribution of atmosphere, oceans and cryosphere, Earth and Planetary Science Letters, 218: 363-377.

Sloan, L.C., Crowley, T.J. and Pollard, D., 1996: Modeling of middle Pliocene climate with the NCAR GENESIS general circulation model, Marine Micropaleontology, 27: 51-61.

For full references please consult:

www.pages-igbp.org/products/newsletter/ref2008_2.html 